\title{
Stability analysis of concrete seawalls against earthquake forces
}

\author{
S. A. Lashteh Neshaei, M. A. Mehrdad \& M. Gholipour Salimi \\ Department of Civil Engineering, Guilan University, Iran
}

\begin{abstract}
Seawalls are commonly constructed to prevent landward erosion of shorelines and maintain configuration of the area behind them against wave action. Recently, rising of sea level particularly in the northern coastline of Iran, has caused special attention to the design and construction of seawalls in that region. One of the important factors in the design of seawalls and stability control of such structures is their safety factor (SF) against overturning. The present study considers all effective parameters on the stability of seawalls, appropriate equations are presented for calculation of the safety factor against overturning. The equations are presented in such a way that designers can easily use them. Furthermore, different design curves are also obtained by sensitivity analysis of seawall stability. The results obtained from this study can be easily implemented and used for design of crucial cases. Also, using the presented equations can be a great help for the optimum design of seawalls against different load combinations, particularly for earthquake forces. The results of the present study clearly indicate that the optimum dimensions for a typical rectangular or trapezoidal concrete seawall, as far as the stability of such structure is concerned, highly depends on the slenderness of the wall (ratio of the wall height to wall width). Increasing this value from a critical range of 1.5 to 2 results in a drastic drop of the safety factor against overturning. Also the presence of earthquake forces enhances this reduction leading to a narrow-bound confidence interval for the safety of concrete seawalls.
\end{abstract}

Keywords: seawall, safety factor, earthquake, wave, overturning.

\section{Introduction}

Since Iran is almost bounded by water (in the North by the Caspian Sea and South by the Persian Gulf) major ports are the basic necessities for these areas. 
These necessities arise from several concerns. One pf these concern, which we may connect it to technical one, is seas run up and water level changes, especially in the northern shores of Iran, which calls for accurate studies of different beach protection methods.

One mode of seawalls failure is their overturning, due to applying different loads. Therefore determination of SF of design is important. Main forces exerting on seawalls include: waves force, hydrostatic force, hydrodynamic force, soil pressure and vertical forces (inertia and uplift).

In this study, at first, forces and formulae are presented. Safety factor is calculated by defining rational and dimensionless parameters through authors own computer programming. The presented formulae are absolutely useful for all design purposes, which can be great time savers and lead to optimum designs.

\section{Governing equations}

The proposed cross section of a gravity seawall is shown in figure 1 . The seawall is subjected to an earthquake motion having peak ground acceleration of $0.3 \mathrm{~g}$ for $50 \%$ probability of exceedance.



Figure 1: $\quad$ Schematic cross section of the seawall.

\subsection{Active soil pressure and thrust}

To consider active soil pressure, Monobe-Okabe [1] equations for partially submerged soil wedge are utilized (figure 2). For a partially submerged soil wedge the equivalent unit weight for the soil wedge may be obtained by computing the weighted average of the unit weights based on the volume of soil in the equivalent specific weight.

$$
\gamma_{e}=\gamma_{\text {wet }}\left[1-\left(\frac{H_{\text {sub }}}{H}\right)^{2}\right]+\gamma_{\text {sat }}\left(\frac{H_{\text {sub }}}{H}\right)^{2}
$$




$$
\begin{gathered}
K_{a e}=\frac{\cos ^{2}(\varphi-\theta-\varphi)}{\cos \psi \cdot \cos ^{2} \theta \cdot \cos (\delta+\theta+\psi) \cdot\left[1+\sqrt{\frac{\sin (\delta+\varphi) \cdot \sin (\varphi-\beta-\psi)}{\cos (\delta+\theta+\psi) \cdot \cos ^{2}(\beta-\theta)}}\right]^{2}} \\
\psi=\operatorname{tg}^{-1}\left[\frac{K_{h}^{\prime}}{1-K_{v}}\right] \\
P_{a e}=1 / 2 K_{a e} \cdot \gamma_{e} \cdot H^{2} \cdot\left(1-K_{v}\right) \\
\alpha_{a e}=\phi+\operatorname{arctg}\left[\frac{-\operatorname{tg} \phi+\sqrt{\operatorname{tg} \phi \cdot(\operatorname{tg} \phi+\cot \phi)(1+\operatorname{tg} \delta \cdot \cot \phi)}}{1+\operatorname{tg} \delta \cdot(\operatorname{tg} \phi+\cot \phi)}\right]
\end{gathered}
$$

where: $\gamma_{b}=$ buoyant unit weight; $K_{h}^{\prime}=$ modified horizontal seismic coefficient; $q_{\text {sur }}=$ a uniformly distributed surcharge; $\alpha_{a e}=$ the active angle of failure from the horizontal direction; $K_{a e}=$ dynamic active soil pressure coefficient; $\psi=$ seismic inertia angle; $\delta=$ friction angle between the backfill and the wall; $\varphi=$ angle of internal friction of the backfill soil; $K_{v}=$ uniform field of vertical coefficient acceleration; $K_{h}=$ uniform field of horizontal coefficient acceleration;

For simplicity, it is often assumed in design practice that $K_{v}=0$ (e.g. Ministry of Transport, Japan, 1989) [1].

The active soil wedge is defined by the angle of failure measured from the vertical direction as:

$$
90-\alpha_{a e}=\text { active soil wedge. }
$$

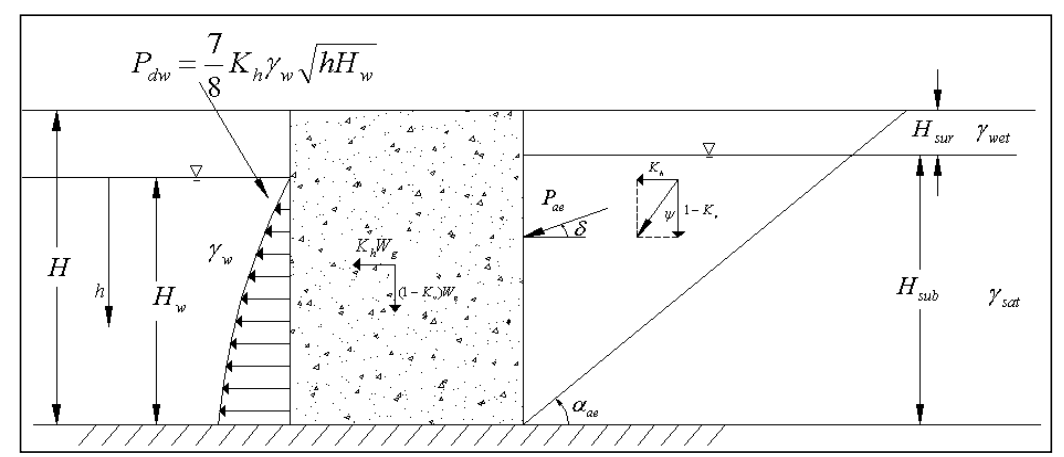

Figure 2: $\quad$ Soil pressures on seawall.

Other forces exerted on the seawall are indicated in table 1. 
Table 1: $\quad$ Forces exerting on seawall.

\begin{tabular}{|c|c|c|}
\hline Force & Utilized Formula(e) & Reference \\
\hline $\begin{array}{c}\text { Hydrodynamic } \\
\text { pressure }\end{array}$ & $P_{d w}=\frac{7}{12} K_{h} \gamma_{w} d^{2}$ & Westergard [1, 2] \\
\hline $\begin{array}{c}\text { Hydrostatic water } \\
\text { pressure }\end{array}$ & $F_{w}=0.5 \gamma_{w} d^{2}$ & {$[3]$} \\
\hline $\begin{array}{c}\text { Waves pressure } \\
\text { (breaking waves) }\end{array}$ & Goda formulae $(2000)$ & {$[4]$} \\
\hline $\begin{array}{c}\text { Waves pressure } \\
\text { (nonbreaking } \\
\text { waves) }\end{array}$ & Sain Flou formulae $(1972)$ & {$[3]$} \\
\hline $\begin{array}{c}\text { Uplift pressure } \\
\text { Inertia }\end{array}$ & $p_{u}=\frac{1}{2}(1+\cos \beta) \alpha_{1} \alpha_{3} \rho g H_{\max }$ & \\
\hline & $F_{I}=\gamma A$ & \\
\hline
\end{tabular}

\section{Sensitivity analysis}

\subsection{Wall height $(y)$ and width $(x)$}

According to figures 3 and 4, while in $(y / x)$ increasing, the quasi linear reduction of SF against overturning can be observed. This leads to changes in quasi parabolic behaviour due to an increase of water depth in front of the seawall.

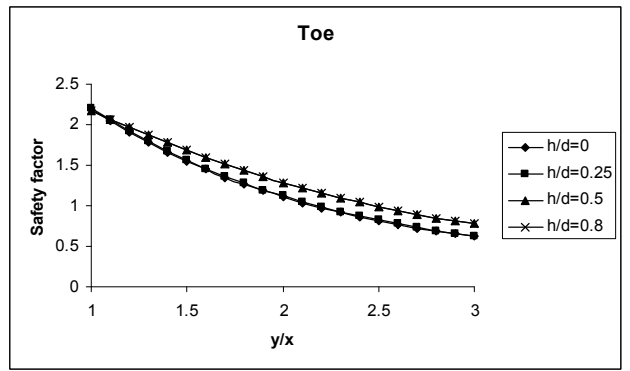

Figure 3: Variation of safety factor against $y / x$ due to different $h / d$ for $d / y=0.25$. 


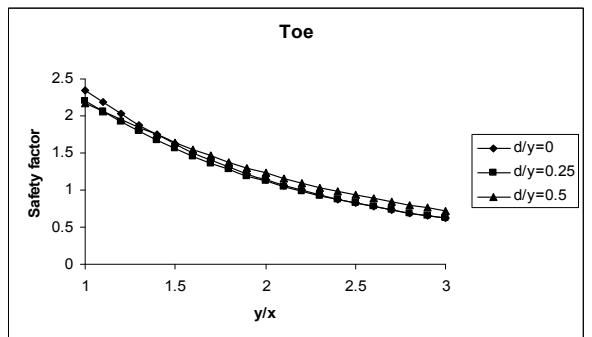

Figure 4: Variation of safety factor against $y / x$ due to different $d / y$ for $h / d=0.25$.

\subsection{Water depth in front of seawall $(d)$}

The following conclusions are obtained based on figures 5 and 6: Increasing water depth in front of seawall up to a specific amount, leads to increasing SF. When water depth reaches to critical point, the SF is then reduced. The more slender the seawall, the less this critical depth would be. Also by rise of the incident wave's height, the critical depth is extremely decreased.

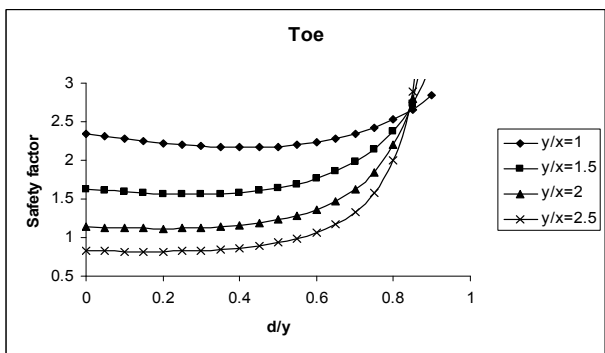

Figure 5: Variation of safety factor against $d / y$ due to different $y / x$ for $h / d=0.25$.

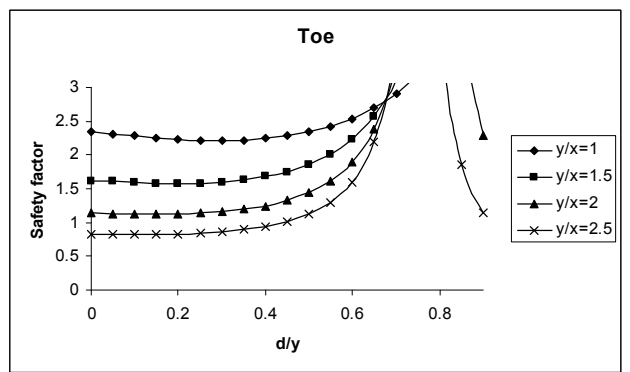

Figure 6: Variation of safety factor against $d / y$ due to different $y / x$ for $h / d=0.5$. 


\subsection{Wave height $(h)$}

Based on figures 7 and 8 , it can be concluded that breaking waves, compared to nonbreaking waves, result in larger safety factors.

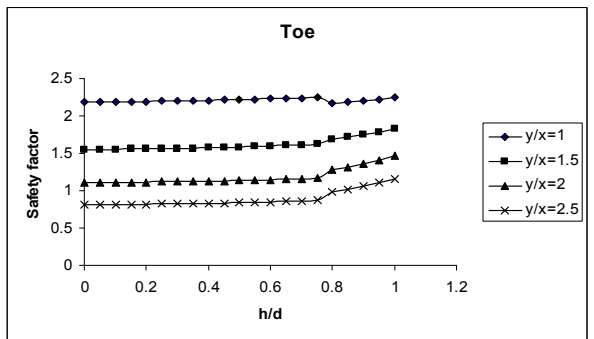

Figure 7: Variation of safety factor against $h / d$ for different $y / x$ for $d / y=0.25$.

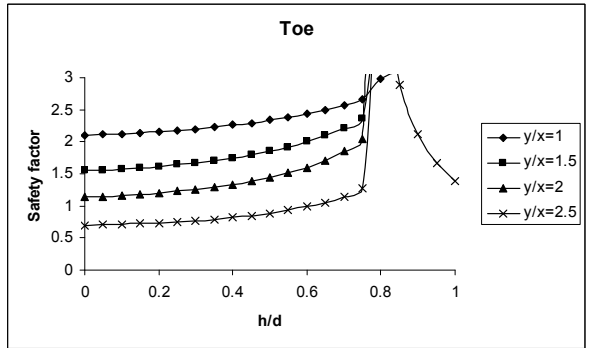

Figure 8: Variation of safety factor against $h / d$ for different $y / x$ for $d / y=0.5$.

\subsection{Seawall slope angle}

According to figures 9 and 10 it can be concluded that slope angle ranging from $50^{\circ}$ to $70^{\circ}$ result in adequate value of safety factor.



Figure 9: Variation of safety factor against seawall slope angle for different $d / y$ for $y / x=1.85$ and $h / d=0.5$. 




Figure 10: Variation of safety factor against seawall slope angle for different $d / y$ for $y / x=1.85$ and $h / d=0.8$.

\subsection{Slope of backfills behind the seawall}

Increasing slope of the embankment behind the seawall leads to reduction in SF against overturning; as indicated in figure 11 .

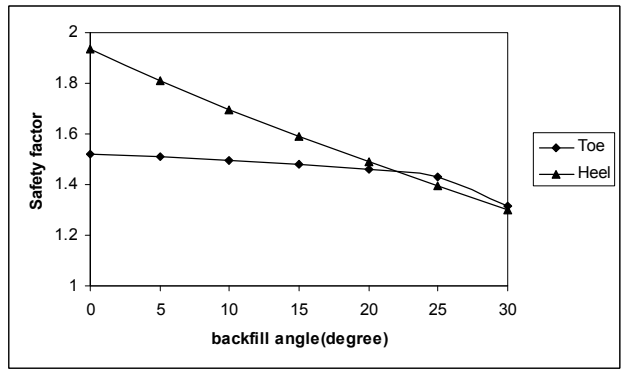

Figure 11: Variation of safety factor against embankment slope angle.

\section{Safety factor of seawalls against overturning}

The allowable SF against overturning is assumed to be more than 1.5 [5]. Based on this assumption the following equation is set up for safety factor which include five independent variables:

$$
S F=f(y, x, d, h, \theta)
$$

To consider the dimensionless parameters, SF can be defined as:

$$
\left.S F=f(y / x, d / y, h / d, \theta) \quad \text { (In vertical seawalls } \theta=0^{\circ}\right)
$$

According to previous figures, the four variables in the function vary in the following domains:

$$
1.5 \leq y / x \leq 2 \quad 0 \leq d / y \leq 0.5 \quad 0 \leq h / d \leq 0.8 \quad 45^{\circ} \leq \theta \leq 90^{\circ}
$$




\subsection{Safety factor around toe of vertical wall in case of nonbreaking waves}

By considering the SF as a second order polynominal function one can write:

$$
S F=a(h / d)^{2}+b(h / d)+c \quad \text {, where, } \quad(d / y=c t e)
$$

To draw variation of coefficients $(a, b$ and $c$ ) against $d / y$, the following formulae are obtained:

$$
a=\sum_{i=0}^{3} a_{i}\left(\frac{d}{y}\right)^{i} \quad b=\sum_{i=0}^{3} b_{i}\left(\frac{d}{y}\right)^{i} \quad c=\sum_{i=0}^{3} c_{i}\left(\frac{d}{y}\right)^{i}
$$

The estimated Values of $a_{i}, b_{i}$ and $c_{i}$, for different $y / x$, are presented in table 2 .

\begin{tabular}{|c|c|c|c|c|c|}
\hline & \multicolumn{4}{|c|}{ Vertical wall, non breaking wave } \\
\hline & & \multicolumn{4}{|c|}{$y / x$} \\
\hline & & 1.5 & 1.65 & 1.85 & 2 \\
\hline \multirow{4}{*}{$a_{i}$} & 0 & 0.121 & 0.133 & 0.156 & 0.167 \\
\hline & 1 & -2.992 & -3.265 & -3.737 & -3.957 \\
\hline & 2 & 11.014 & 11.806 & 13.038 & 13.570 \\
\hline & 3 & 0.000 & 0.000 & 0.000 & 0.000 \\
\hline \multirow{4}{*}{$b_{i}$} & 0 & -0.004 & 0.005 & -0.006 & -0.006 \\
\hline & 1 & 0.114 & 0.137 & 0.161 & 0.174 \\
\hline & 2 & -0.222 & -0.316 & 0.419 & 0.478 \\
\hline & 3 & 0.000 & 0.000 & 0.000 & 0.000 \\
\hline \multirow{4}{*}{$c_{i}$} & 0 & 1.626 & 1.459 & 1.267 & 1.147 \\
\hline & 1 & -0.495 & -0.439 & -0.380 & -0.403 \\
\hline & 2 & 0.765 & 0.776 & 0.779 & 0.882 \\
\hline & 3 & 0.000 & 0.000 & 0.000 & 0.000 \\
\hline
\end{tabular}

Table 2: $\quad$ Coefficients of $a_{i}, b_{i}$ and $c_{i}$ for eqn. (10).

\subsection{Safety factor around toe of slope wall in the case of nonbreaking waves}

For the case of $y / x=$ cte, the SF can be written as

$$
S F=f(d / y, h / d, \theta)
$$

By comparing the variation of $S F$ due to $\theta$, it is observed that in all conditions, a second order polynominal function can be regressed on the base of convergence index of 0.95 .

$$
S F=A \theta^{2}+B \theta+C
$$

Values of $A$ are indicated in table 3. 
Table 3: $\quad$ Values of $A$ in eqn. (12).

\begin{tabular}{|c|c|c|c|c|c|}
\hline \multicolumn{6}{|c|}{ Slope seawall, nonbreaking waves } \\
\hline \multirow{2}{*}{$\mathrm{y} / \mathrm{x}$} & \multicolumn{2}{|c|}{$0<\mathrm{d} / \mathrm{y} \leq 0.5$} & \multicolumn{2}{|c|}{$0<\mathrm{h} / \mathrm{d} \leq 0.8$} & $A^{*} 10^{-4}$ \\
\hline \multirow{3}{*}{1.5} & 0 & 0.3 & 0 & 0.8 & -3 \\
\cline { 2 - 6 } & 0.3 & 0.5 & 0 & 0.6 & -3 \\
\cline { 2 - 6 } & 0.3 & 0.5 & 0.6 & 0.8 & -3.3 \\
\hline \multirow{3}{*}{1.65} & 0 & 0.3 & 0 & 0.8 & -3.2 \\
\cline { 2 - 6 } & 0.3 & 0.5 & 0 & 0.6 & -3.2 \\
\cline { 2 - 6 } & 0.3 & 0.5 & 0.6 & 0.8 & -3.6 \\
\hline \multirow{3}{*}{2} & 0 & 0.3 & 0 & 0.8 & -3.3 \\
\cline { 2 - 6 } & 0.3 & 0.5 & 0 & 0.4 & -3.4 \\
\cline { 2 - 6 } & 0.3 & 0.5 & 0.4 & 0.8 & -4 \\
\hline & 0 & 0.4 & 0 & 0.8 & -3.5 \\
\cline { 2 - 6 } & 0.4 & 0.5 & 0 & 0.4 & -3.5 \\
\cline { 2 - 6 } & 0.4 & 0.5 & 0.4 & 0.8 & -4.2 \\
\hline
\end{tabular}

To draw variation of $B$ and $C$ against $h / d$ due to different $d / y$, the following formulae are obtained:

$$
B=\sum_{i=0}^{2} B_{i}\left(\frac{h}{d}\right)^{i} \quad C=\sum_{i=0}^{2} C_{i}\left(\frac{h}{d}\right)^{i}
$$

$B_{i}$ and $C_{i}$ are functions of $d / y$ that can be written in form of $3^{\text {rd }}$ order polynominal function.

$$
B_{i}=\sum_{j=0}^{3} b_{j}\left(\frac{d}{y}\right)^{j} \quad C_{i}=\sum_{j=0}^{3} c_{j}\left(\frac{d}{y}\right)^{j}
$$

The estimated values of $b_{i}$ and $c_{i}$ can be calculated in the same way as values of coefficients in eqn. (9).

\subsection{Safety factor around toe of slope wall, in the case of nonbreaking waves}

In case of $h / d \geq 0.8$, where waves are broken [6], the safety factor can be written as

$$
S F=f(y / x, d / y, \theta)
$$

The following formula is used to assess the variation of SF against slope of the structure due to different values of $d / y$ and $y / x$ :

$$
S F=a \theta^{2}+b \theta+c
$$

The estimated values for $a, b$ and $c$ are presented in table 4 . 
Table 4: $\quad$ Coefficients of $a, b$ and $c$ for eqn. (16).

\begin{tabular}{|c|c|c|c|c|c|}
\cline { 3 - 6 } \multicolumn{2}{c|}{} & \multicolumn{4}{c|}{ Slope seawall, breaking waves } \\
\cline { 3 - 6 } \multicolumn{2}{c|}{} & \multicolumn{4}{c|}{$y / x$} \\
\hline \multirow{4}{*}{$a$} & 0 & 0.000 & 0.000 & -0.001 & 0.000 \\
\cline { 2 - 6 } & 1 & 0.002 & 0.002 & 0.009 & -0.001 \\
\cline { 2 - 6 } & 2 & -0.010 & -0.010 & -0.045 & -0.005 \\
\cline { 2 - 6 } & 3 & 0.017 & 0.017 & 0.067 & 0.017 \\
\hline \multirow{4}{*}{$b$} & 0 & 0.045 & 0.050 & 0.057 & 0.062 \\
\cline { 2 - 6 } & 1 & -0.202 & -0.275 & -0.377 & -0.464 \\
\cline { 2 - 6 } & 2 & 1.110 & 1.510 & 2.075 & 2.550 \\
\cline { 2 - 6 } & 3 & -1.533 & -2.117 & -2.950 & -3.650 \\
\hline \multirow{4}{*}{$c$} & 0 & 0.813 & 0.572 & 7.085 & 0.037 \\
\cline { 2 - 6 } & 1 & 2.595 & 4.380 & 7.085 & 9.324 \\
\cline { 2 - 6 } & 2 & -22.315 & -31.590 & -45.635 & -57.195 \\
\cline { 2 - 6 } & 3 & 33.400 & 46.517 & 66.470 & 82.917 \\
\hline
\end{tabular}

\section{Final equations}

The final equations for calculating concrete seawalls, SF against overturning are summarized as:

- $\quad$ Vertical wall - nonbreaking wave

$$
S F=a(h / d)^{2}+b(h / d)+c
$$

- Vertical wall - breaking wave

$$
\begin{array}{ll}
0 \leq d / y \leq 0.4 & S F=a(y / x)^{2}+b(y / x)+c \\
0.4 \leq d / y \leq 0.5 & S F>3
\end{array}
$$

- $\quad$ Slope wall - nonbreaking wave

$$
\begin{gathered}
S F=A \theta^{2}+B \theta+C \\
A=\text { cte } \quad B=\sum_{i=0}^{2} B_{i}\left(\frac{h}{d}\right)^{i} \quad C=\sum_{i=0}^{2} C_{i}\left(\frac{h}{d}\right)^{i} \\
B_{i}=\sum_{j=0}^{3} b_{j}\left(\frac{d}{y}\right)^{j} \quad C_{i}=\sum_{j=0}^{3} c_{j}\left(\frac{d}{y}\right)^{j}
\end{gathered}
$$

- $\quad$ Slope wall - breaking wave 


$$
\begin{array}{ll}
0 \leq d / y \leq 0.4 & S F=a \theta^{2}+b \theta+c \\
0.4 \leq d / y \leq 0.5 & S F>2
\end{array}
$$

In all above formulae:

$$
a=\sum_{i=0}^{3} a_{i}\left(\frac{d}{y}\right)^{i} \quad b=\sum_{i=0}^{3} b_{i}\left(\frac{d}{y}\right)^{i} \quad c=\sum_{i=0}^{3} c_{i}\left(\frac{d}{y}\right)^{i}
$$

\section{Summary}

This study comes up with the following:

1. By increasing $y / x$, a quasi linear deduction of SF is observed, which will change into parabolic behavior with rising of water depth.

2. It is recommended that the ratio of height to width in seawalls is better not to be more than 2 .

3. The equilibrium point of water pressure and soil lateral pressure play an important role in determining magnitude of SF, while, by increasing slenderness of seawall $(y / x)$, the allowable minimum water depth will increase.

4. In most conditions, breaking waves result in a larger SF in comparison to non breaking waves.

5. Waves can influence SF only if water depth in front of seawall is considerable (minimum water depth should be more than 25 percent of seawall height).

6. The optimum sections proposed for design of seawalls are indicated in table 5 ( $\theta=$ angle between seawall basement and horizontal line).

Table 5: $\quad$ Relation between $\theta$ and $\frac{w}{h}$.

\begin{tabular}{|c|c|c|c|c|}
\hline Angle & $85 \leq \theta \leq 90$ & $75 \leq \theta<85$ & $60 \leq \theta<75$ & $\theta \leq 60$ \\
\hline$\frac{w(\text { width })}{h \text { (height })}$ & 0.5 & 0.375 & 0.25 & Not recommended \\
\hline
\end{tabular}

\section{References}

[1] Pianc, Siesmic Design Guidelines for Port Structures, Working Group No. 34 of the Maritime Navigation Commission, International Navigation Association, A. A. Balkema Publishers/Lisse/Abingdon/Exton (PA)/Tokyo, 2001.

[2] Chen, B.F. and Haung, C.F., Hydrodynamic Forces on Concrete Seawall and Breakwater during Earthquake, Ocean Engineering Journal, Volume 29, pp. 783-814, 2002. 
[3] Goda, Y., Advanced Series on Ocean Engineering-Volume 15, Random Seas and Design of Maritime Structures, World Scientific Publishing Co. Pte. Ltd, 2000.

[4] Quinn, A.D., Design and Construction of Ports and Marine Structures, Second Edition, McGraw-Hill Book Company, 1972.

[5] Wang, W., Han, Z. and Liang, G., Safety Analysis of Overall Stability of Qiantang Estuary Seawall, Proc. of the Int. Conf. on Estuaries and Coasts, Hangzhou, China, Nov. 2003.

[6] Dean, G.R. and Dalrymple, A.R., Advanced Series on Ocean EngineeringVolume 2, Water Wave Mechanics for Engineering and Scientists, World Scientific Publishing Co. Pte. Ltd, 1991. 